\title{
Rosmarinic Acid Accumulation and Antioxidant Potential of Dracocephalum moldavica L. Cell Suspension Culture
}

\author{
Izabela WEREMCZUK-JEŻYNA ${ }^{1 *}$, Izabela GRZEGORCZYK- \\ $\mathrm{KAROLAK}^{1}$, Barbara FRYDRYCH${ }^{2}$, Katarzyna HNATUSZKO-KONKA ${ }^{3}$, \\ Aneta GERSZBERG ${ }^{3}$, Halina WYSOKIŃSKA ${ }^{1}$ \\ ${ }^{I}$ Medical University of Łódź, Department of Biology and Pharmaceutical Botany, Muszyńskiego 1, 90-151 Eódź, Poland; izabela.weremczuk- \\ jezyna@umed.lodz.pl (*correspondingauthor);izabela.grzegorczyk@umed.lodz.pl; halina.wysokinska@umed.lodz.pl \\ ${ }^{2}$ Medical University of Łódź, Muszyńskiego 1, Department of Toxicology, 90-151 Łódź, Poland; barbara.frydrych@umed.lodz.pl \\ ${ }^{3}$ University of Łódź, Faculty of Biology and Environmental Protection, Department of Genetics, Plant Molecular Biology and Biotechnology, \\ Banacha Street 12/16,90-237 Lodz, Poland; aneta.gerszberg@biol.uni.lodz.pl; katarzyna.hnatuszko@biol.uni.lodz.pl
}

\begin{abstract}
Dracocephalum moldavica L. (Lamiaceae) is known for its medicinal properties; however greater yields can potentially be achieved by in vitro cultivation. A cell suspension culture of $D$. moldavica L. (Lamiaceae) derived from root-derived callus was established in liquid MS medium supplemented with 2,4-D $0.5 \mathrm{mg} / 1$ and BAP $0.2 \mathrm{mg} / \mathrm{l}$. The biomass and rosmarinic acid (RA) content were analyzed during the 15-day growth cycle of the culture. The highest fresh and dry weight (14.29 g/flask and $1.14 \mathrm{~g} /$ flask, respectively) and RA level $(27.2 \mathrm{mg} / \mathrm{g} \mathrm{DW})$ were reached at day $12 \mathrm{of}$ culture. Methanolic extracts of the culture were assayed for total phenolic content using the Folin-Ciocalteau method, and antioxidant activities using three in vitro tests: ABTS radical scavenging, ferric ion reduction (FRAP) and lipid peroxidation (LPO). RA content and antioxidant potential were found to be higher in cell suspension culture than in root-derived callus. The cell suspension culture also exhibited higher concentrations of RA and ABTS radical scavenging activity than those of the aerial parts of six-month-old field-grown plants of $D$. moldavica. The overall results show a significant correlation between antioxidant activity, total phenolic content and RA content of the examined extracts. The study presents for the first time the use of cell cultures of $D$. moldavica for production of therapeutically-valuable metabolites. Our results suggest that the obtained culture could be considered as a potential source of rosmarinic acid, a compound known for its strong antioxidant activity.
\end{abstract}

Keywords: antioxidant activity, D. moldavica, phenolic content, undifferentiated in vitro culture, UPLC

\section{Introduction}

Dracocephalum moldavica L. is an annual aromatic plant of the Lamiceae family. This plant is native to Siberian and Central Asia, it also grows in Egypt, China and Mongolia at altitudes of up to 2700-3100 m above sea level (Nikitina et al., 2008). D. moldavica is naturalized in Eastern and Central Europe (Kakasy et al., 2006). Its aerial parts have been widely utilized in traditional medicine for the treatment of stomach and liver disorders as well as headache and toothache (Dastmalchi et al., 2007). Studies indicate that D. moldavica extracts have anti-Helicobacter pylori activity (Ghannadi et al., 2004) as well as sedative, analgesic and wound-healing properties (Sultan et al., 2008). The main substances responsible for the therapeutic effects of the $D$. moldavica aerial parts are phenolic acids (mainly rosmarinic, caffeic and ferulic acids), flavonoids and essential oil components (Kakasy et al., 2006; Popova et al., 2008; Sultan et al., 2008). Flavonoids and phenolic acids are known to be beneficial to human health and disease prevention thanks to their strong antioxidant activity, capacity to scavenge free radicals and ability to neutralize reactive oxygen species (Saxena et al., 2012). One of the most prominent phenolic compounds in D. moldavica is rosmarinic acid. RA is known to have antioxidant, antimicrobial, antiinflammatory and antiviral properties (Bais et al., 2002; Ly et al., 2006). There are reports on RA activity against Herpes simplex virus (Sanches-Medina et al., 2007) and Human immunodeficiency virus (HIV-1) (Astani et al., 2012). Other authors have reported RA to have hepatoprotective (Lima et al., 2006) and cardioprotective properties (Psotova et al., 2005) and for it to play a role in the prevention of Alzheimer's disease (Hamaguchi et al., 2009). There is a need to produce large 
216

amounts of the valuable compound, and biotechnological methods represent attractive and cost-effective alternatives to field cultivation. Rosmarinic acid has been synthesized in callus and cell suspension cultures from a range of plant species including Ocimum sanctum (Hakkim et al., 2011), Coleus blumei (Qian at al., 2009) or Salvia milttiorbiza (Wu et al., 2016).

The present study describes the establishment of a $D$. moldavica cell-suspension culture and determines its ability to biosynthesize RA. It compares RA production in cell suspension culture, callus culture and in field-grown $D$. moldavica plants. The antioxidant potential of these plant materials was investigated in vitro using three different tests. The total content of phenolic compounds, expressed in milligrams gallic acid equivalents per gram dry weight of methanolic extract in D. moldavica plant materials, was also determined.

\section{Materials and Methods}

\section{Plant material}

Dracocephalum moldavica seeds were obtained from the Botanical Garden of Lublin (Poland). They were sterilized with $2 \%$ sodium hypochlorite solution for two minutes and after rinsing with sterile distilled water, the seeds were germinated in the dark at $26{ }^{\circ} \mathrm{C}$ on MS (Murashige and Skoog, 1962) agar $(0.7 \%)$ medium supplemented with sucrose (30 g/l), $0.02 \mathrm{mg} / \mathrm{l}$ kinetin and $1.0 \mathrm{mg} / \mathrm{l}$ giberellic acid. After germination, the seedlings were transferred into light conditions (16 hour light / 8 hour dark; cool fluorescent lamps; $\left.40 \mu \mathrm{m} \mathrm{m}^{-2} \mathrm{~s}^{-1}\right)$. The roots of two-week-old seedlings were used for callus induction.

The seeds were also used to obtain field-grown $D$. moldavica plants. After six months, their aerial parts were harvested and used in this study. Voucher specimens have been deposited at the Department of Biology and Pharmaceutical Botany, Medical University of Łódź

\section{Establishment of callus and cell suspension culture}

Callus of $D$. moldavica from the roots of two-week-old seedlings was obtained on solid agar (0.7\%) MS medium with $0.5 \mathrm{mg} / \mathrm{l}$ 2.4-D (2.4-dichlorophenylacetic acid) and $0.2 \mathrm{mg} / \mathrm{l}$ BAP (6-benzylaminopurine). The callus was subcultured at twoweek intervals. For initiation of cell suspension culture, about $2 \mathrm{~g}$ fresh weight (FW) of callus from passage 10 was transferred into $80 \mathrm{ml}$ of MS liquid medium supplemented with the same concentration of growth regulators as in the solid medium. The culture was maintained in $300 \mathrm{ml}$ Erlenmeyer flasks on a rotary shaker $(100 \mathrm{rpm})$ and subcultured every 14 days using inoculum of about $500 \mathrm{mg}$ fresh weight per flask. The cultures were kept at $26 \pm 2{ }^{\circ} \mathrm{C}$ under a 16 -hour photoperiod provided by cool white fluorescent lamps (approximately $40 \mu \mathrm{m} \mathrm{m}^{-2} \mathrm{~s}^{-1}$ ).

\section{Analysis of cell suspension culture on growth and $R A$ content}

Every three days for 15 days, three flasks of cell culture were harvested, and the fresh and dry weights (DW) and RA content were determined. All measurements were repeated three times in three successive subcultures (16-18).

\section{Extraction and determination of $R A$}

Lyophilized and powdered plant materials (i.e. callus, cells from suspension culture and aerial parts of $D$. moldavica six- month-old plants grown in the field; $150 \mathrm{mg}$ for UPLC analysis and $1 \mathrm{~g}$ for antioxidant studies), were extracted three times with $70 \% \mathrm{MeOH}(25 \mathrm{ml})$ for 10 minutes at room temperature using an ultrasonic bath (Janicsàk et al., 1999). After filtration, the extracts were combined and evaporated to dryness under reduced pressure.

\section{UPLC analysis of $R A$}

Analysis was performed using an Acquity Ultra Performance Liquid Chromatograph (Waters) equipped with a photodiode array, a UV-visible detector and an autoinjector, according to Lamien-Meda et al. (2010). Separation was performed on a Shield RP C18-column $(2.19 \times 100 \mathrm{~mm}, 1.7 \mathrm{~lm}$ pore size $)$ at a column temperature of $35^{\circ} \mathrm{C}$. The solvent gradient used in this study comprised $1 \%$ acetic acid : acetonitrile $85: 15 \mathrm{v} / \mathrm{v}$ as solvent $\mathrm{A}$, and methanol as solvent $\mathrm{B}$. The flow rate was $0.43 \mathrm{ml} / \mathrm{min}$ and wavelength used for RA detection was $360 \mathrm{~nm}$. RA was identified by comparing its UV spectrum, retention time (3.8 $\mathrm{min}$ ) and LC-MS/MS (liquid chromatography-mass spectrometry) data with those of a standard compound (ChromaDexTM). The detailed procedure for the identification and quantification of RA is described in a previous paper (Weremczuk-Jeżyna et al., 2013).

\section{Totalphenolic content}

Total phenolic content was estimated using a colorimetric method based on Folin-Ciocalteu (POCH) reagent, as described by Singlenton et al. (1965). Absorbance at $765 \mathrm{~nm}$ was measured after 30 minutes of incubation at room temperature. Quantification was performed against a standard calibration curve for gallic acid. The results were expressed as gallic acid (Sigma-Aldrich) mg equivalents per gram of dry extract (GAE $\mathrm{mg} / \mathrm{gDW}$ of extract).

\section{Antioxidant Assays \\ FRAP (ferricion reducing activity)}

The FRAP was determined according to Pulido et al. (2000) methods with some modifications. The absorbance was measured at $595 \mathrm{~nm}$. The antioxidant activity was evaluated against a calibration curve of $0-2000 \mu \mathrm{M}$ for a standard with a known FRAP value: ferrous sulphate. The detailed procedure is described by Grzegorczyk-Karolak et al. (2015a). Ferric reducing power was expressed in $\mu \mathrm{M} \mathrm{Fe}(\mathrm{II}) \mathrm{g} / \mathrm{DW}$ of extract.

\section{ABTS radical scavenging}

The antioxidant activity was also determined using the ABTS radical cation decolourisation test as described by Grzegorczyk-Karolak et al. (2015b). The absorbance was measured after 10 minutes at $734 \mathrm{~nm}$. The results were expressed as $\mathrm{EC}_{50}$ : the concentration of sample at which $50 \%$ of maximum scavenging activity was recorded.

\section{Linoleic acid peroxidation inbibition}

The experiment was carried out according to Choi et al. (2002) with some modifications. The absorbance of the reaction mixture was measured at $532 \mathrm{~nm}$. The percentage of linoleic acid peroxidation inhibition was calculated using the following equation: $\%$ inhibition $=\mathrm{Abs}_{\text {control }}-\mathrm{Abs}_{\text {sample }}-\mathrm{Abs}$ extract $) \times 100 / \mathrm{Abs}$ control, where $\mathrm{Abs}_{\text {control }}$ includes methanol instead of sample, $\mathrm{Abs}_{\text {extract }}$ - absorbance of sample where linoleic acid solution was replaced by methanol. 


\section{Statistical analysis}

All results were calculated as means \pm standard error. The means were compared using the Kruskall-Wallis test. $\mathrm{EC}_{50}$ and the correlation coefficients $(\mathrm{r})$ between the antioxidant assay, the total phenolic content and RA content were calculated using MS-Excel software. Any differences were regarded as significant at $\mathrm{p}<0.05$.

\section{Results and Discussion}

Root-derived friable callus was used to initiate the $D$. moldavica of cell suspension culture. The cell culture was grown in MS liquid medium supplemented with 2,4-D 0.5 $\mathrm{mg} / \mathrm{l}$ and BAP $0.2 \mathrm{mg} / \mathrm{l}$. UPLC examination found rosmarinic acid to be the major phenolic compound (retention time 3.8 min) of the methanolic extract. RA content and biomass on the basis of fresh and dry weight were recorded at intervals of three days during the 15-day culture period. As shown in Fig. 1a, the culture was in a lag phase for the first three days, before growing exponentially until day 12 of the culture period. Both fresh and dry biomass demonstrated similar growth curves. The highest fresh weight $(14.29 \mathrm{~g} /$ flask; 28 times the inoculated biomass) and dry weight (1.14 g/flask; 23 times), were achieved on day 12. Following this, biomass began to decline and brown, with cell death observed at day 15, which may be due to the oxidation of phenolic compounds, the consumption of nutrients and lack of oxygen in the medium (Kajani et al., 2012; Saharoo et al., 2016). The level of RA in the cell suspension culture was not affected for the first nine days of cultivation (Fig. 1b). A fast increase in RA content was observed between days 9 and 12 of the culture period, when the compound concentration enhanced from $8.4 \mathrm{mg} / \mathrm{g}$ to 27.2 $\mathrm{mg} / \mathrm{g}$ DW; about 3.7-fold greater than the inoculum value. The results presented in Fig. 1. indicate a correlation between biomass and RA production because both maximum growth and RA content were reached at the same time of growth cycle (day 12). Other authors have also shown similar patterns of RA accumulation in plant cell cultures. For example, in cell suspension of Eringium planum, the highest RA content was observed at the end of the linear growth phase, and this decreased when the culture reached the stationary phase (Kikowska et al., 2012). Similar observations were made for cell suspension cultures of Menthapiperita (Krzyżanowska et al., 2012).

As shown Fig. 2, the RA content in the D. moldavica cell suspension culture was $48 \%$ higher than in callus culture, grown on agar solidified MS medium with the same composition. The difference may be due to the consistency of medium and shear stress during agitations (Zhong et al., 1995). RA level in suspension culture was also found to be $26 \%$ higher than in the aerial parts of intact six-month-old field-grown $D$. moldavica and about twice the RA content detected by Fattahi et al. (2013) in D. kotschyi plants. The production of high amounts of rosmarinic acid has been described earlier in cell cultures of plants belonging to the Lamiceae family, for example with suspension cultures of $S$. officinalis accumulating about $20 \mathrm{mg} / \mathrm{g}$ DW (Grzegorczyk et al., 2005) and $S$. miltiorrhiza about $28 \mathrm{mg} / \mathrm{g}$ DW of RA (Wu et al., 2016). High rosmarinic acid content was also found in $O$. basilicum cell culture $(10 \mathrm{mg} / \mathrm{g} \mathrm{DW})$, this level being 10 times greater than that observed in the callus of the plant (Kintzios et al., 2003).
- - FW $\longrightarrow$ DW
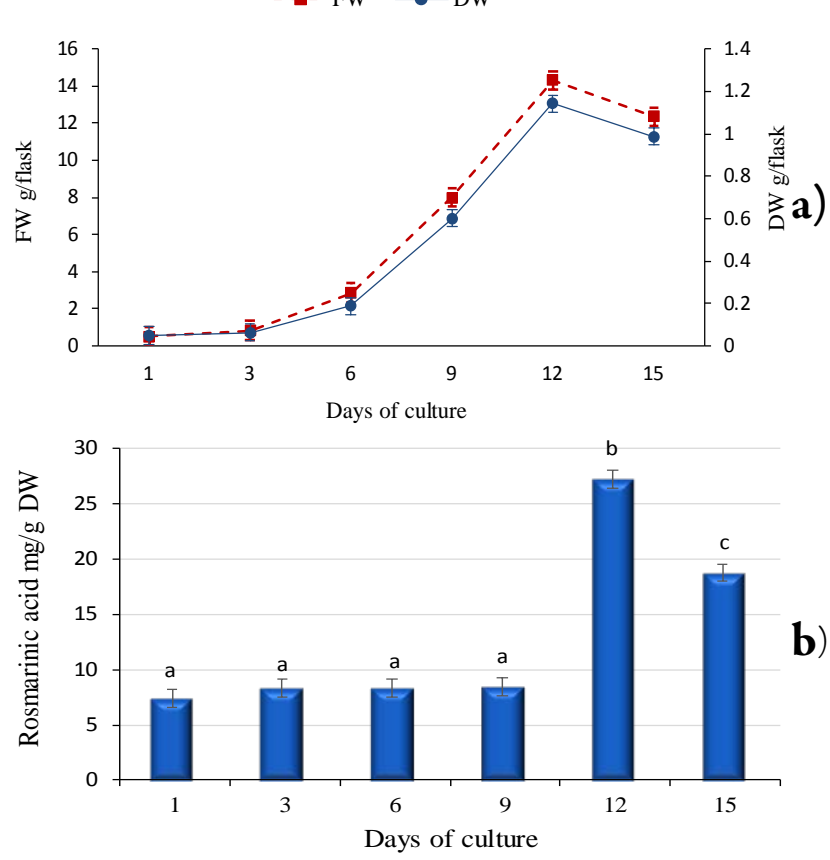

Fig. 1. Growth kinetics (a) and rosmarinic acid content (b) in cell suspension culture of $D$. moldavica grown in liquid MS medium supplemented with 2,4-D $0.5 \mathrm{mg} / \mathrm{l}$ and BAP $0.2 \mathrm{mg} / \mathrm{l}$ for 15 days. Each value is the mean of three replications \pm SE. Means followed by various letters for were significantly different at $\mathrm{p} \leq 0.05$ (Kruskall-Wallis test)

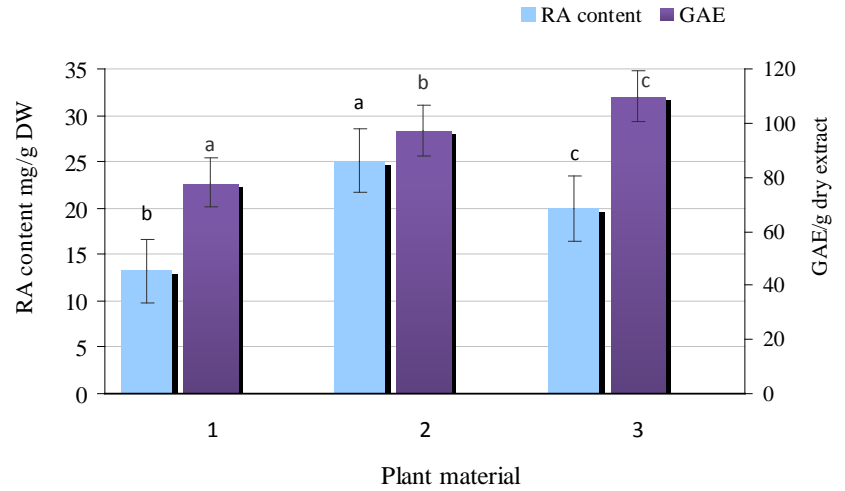

Fig. 2. RA and total phenolic content in callus (1), cell suspension culture (2) and aerial parts of plants of $D$. moldavica (3). Each value represents the mean of three replicates \pm SE. Means followed by various letters for the same parameter were significantly different at $\mathrm{p} \leq 0.05$ (KruskallWallis test). Callus and cell suspension cultures were grown in/on MS medium supplemented with 2,4-D $0.5 \mathrm{mg} / \mathrm{l}$ and IAA $0.2 \mathrm{mg} / \mathrm{l}$. D. moldavica plants were cultivated in the field for six months

\section{Antioxidant activity and total phenolic contents}

A comparative analysis of the antioxidant potential of methanolic extracts from cell suspension, callus cultures and shoots of intact plants of $D$. moldavica is presented in Table 1 . Three in vitro tests based on hydrogen donation or electron donation were used to fully characterize the antioxidant properties of the analyzed extracts. The free radical scavenging 
Table 1. Antioxidant capacities of D. moldavica methanolic extracts

\begin{tabular}{lccc}
\hline & & Extracts from & \\
\cline { 2 - 4 } Assay & Callus culture & Suspension culture & Aerial parts of plants \\
\hline 1ABTS $(\mathrm{EC} 50 \mu \mathrm{g} / \mathrm{ml})$ & $61.75 \pm 8.08 \mathrm{a}$ & $39.64 \pm 5.55 \mathrm{~b}$ & $42.82 \pm 0.68 \mathrm{~b}$ \\
2FRAP $(\mu \mathrm{mol} \mathrm{Fe}(\mathrm{II}) / \mathrm{g} \mathrm{gDW})$ & $1018.66 \pm 30.92 \mathrm{a}$ & $1617.96 \pm 18.72 \mathrm{~b}$ & $1739.36 \pm 54.37 \mathrm{c}$ \\
3LA peroxidation $(\%)$ inhibition $)$ & $4.14 \pm 0.02 \mathrm{a}$ & $13.69 \pm 0.03 \mathrm{~b}$ & $13.69 \pm 0.04 \mathrm{~b}$ \\
\hline The means with the same letter do not differ statistically according to Kruskall-Wallis test $(\mathrm{p} \leq 0.05)$ & \\
${ }^{1}$ EC 50 - amount of extract needed to decrease of the initial ABTS concentration by $50 \%$ & \\
${ }^{2}$ Ferric reducing antioxidant power & & \\
${ }^{3}$ Inhibition ratio of LA peroxidation after incubation with extract concentration of $100 \mu \mathrm{g} / \mathrm{ml}$
\end{tabular}

activity was evaluated by ABTS assay and results were expressed as $\mathrm{EC}_{50}$ values. The methanolic extract of $D$. moldavica suspension culture was found to have stronger antiradical activity $\left(\mathrm{EC}_{50}=39.64 \mu \mathrm{g} / \mathrm{ml}\right)$ than extracts of the callus $\left(\mathrm{EC}_{50}=61.75 \mu \mathrm{g} / \mathrm{ml}\right)$ or aerial parts $\left(\mathrm{EC}_{50}=42.82\right.$ $\mu \mathrm{g} / \mathrm{ml})$. The FRAP assay was used to measure the capacity of the extracts to reduce iron ions $\left(\mathrm{Fe}^{3+}\right.$ to $\left.\mathrm{Fe}^{2+}\right)$, with the results expressed as $\mu \mathrm{mol}$ ferrous ion equivalents per gram of extract dry weight. The extract from the cell suspension culture was found to have greater reductive potential than the callus extract. However, the greatest reducing activity was found for the extract from the aerial parts of $D$. moldavica plants (Table 1).

The inhibition of lipid peroxidation test (LPO) was also performed to evaluate the antioxidant properties of the $D$. moldavica extracts. Although the callus extract was found to have the least ability to inhibit oxidation of linoleic acid, the other extracts were also weak inhibitors of LA peroxidation (max. 14\%) (Table 1). These results suggest that the analysed D. moldavica extracts utilize rather the SET (single electron transfer) reaction mechanism than HAT (hydrogen atom transfer). The antioxidant activity of methanolic extracts from hairy roots of $D$. moldavica has been examined in a previous work (Weremczuk-Jeżyna et al., 2013). However, as different tests were used, it is difficult to directly compare the two sets of results. Various phenolic compounds, including RA, are known to take part in antioxidant activities such as free radical scavenging, acting as reducing agents and protecting cells against lipid peroxidation (Mushtaq et al., 2014). The greatest total phenolic contents (TPC) of $D$. moldavica extracts, as determined by the Folin-Cicoltaeu method and expressed in milligram gallic acid equivalents per gram dry weight of sample, were found in the extract from aerial parts of field-grown $D$. moldavica plants $(110.1 \mathrm{mg}$ GAE/g DW extract); this amount being about $13 \%$ higher than that found in cell suspension culture extract and $41 \%$ higher than in callus culture extract (Fig. 2). The correlation coefficients $(r)$ between the antioxidant activity of the analyzed extracts, total phenolic ( -0.89 for ABTS, 0.93 for FRAP and 0.99 for LPO test) and RA contents ( -0.86 for ABTS, 0.56 for FRAP and 0.94 for LPO assay) indicate that phenolic compounds and RA are the most active components of $D$. moldavica extract with regard to its antioxidant potential. The antioxidant activity of RA can be attributed to its chemical structure, characterized by the presence of two catechol rings connected with phenolic acid (Brewer, 2011).

\section{Conclusions}

Our results indicate that it is possible to obtain a large biomass $(178.6 \mathrm{~g} / \mathrm{l})$ with a high level of RA $(27.2 \mathrm{mg} / \mathrm{gDW})$ in a relatively short time (12 days) using $D$. moldavica cell suspension culture. This cell suspension culture is therefore a good candidate for in vitro RA production. In addition, the ABTS assay of the methanolic extract of the $D$. moldavica cell suspension culture found it to have significant in vitro radical scavenging potential, suggesting that it may have beneficial value in the elimination of free radicals and could play a significant role in protecting cells from oxidative stress.

\section{References}

Astani A, Reichling J, Schnitzler P (2012). Melissa officinalis extract inhibits attachment of herpes simplex virusin vitro. Chemotherapy 58:70-77.

Bais HP, Walker TS, Schweizer HP, Vivanco JM (2002). Root specific elicitation and antimicrobial activity of rosmarinic acid in hairy root cultures of Ocimum basilicum. Plant Physiology and Biochemistry 40:983-995.

Brewer MS (2011). Natural antioxidant: sources, compounds, mechanism of action, and potential applications. Comprehensive Reviews in Food Science and Food Safety 10:221-247.

Choi Ch, Kim SC, Hwang SS, Choi BK, Ahn HJ, Lee MY, Park SH, Kim SK (2002). Antioxidant activity and free radical scavenging capacity between Korean medicinal plants and flavonoids by assay-guided comparison. Plant Science 163:1161-1168.

Dastmalchi K, Dorman HJD, Kosar M, Hiltunen R (2007). Chemical composition and in vitro antioxidant evaluation of water-soluble Moldavian balm (Dracocephalum moldavica L.) extract. Food Science and Technology 40:239-248.

Fattahi M,Nazeri V,Torras-Claveria L, Sefidkon F, Cusido RM,Zamani Z, Palazon J (2013). Identification and quantification of leaf surface flavonoids in wild-growing populations of Dracocephalum kotschyi by LC-DAD-ESI-MS. Food Chemistry 141:139-142

Ghannadi A, Sajjadi SE, Abedi D, Yousefi J, Daraei-Ardekami R (2004). The in vitro activity of seven Iranian plants of the Lamiaceae family against Helicobacter pylori. Nigerian Journal of Natural Products and Medicine 8:40-42

Grzegorczyk I, Bilichowski I, Mikiciuk-Olasik E, Wysokińska H (2005). In vitro cultures of Salvia officinalis $\mathrm{L}$. as a source of antioxidant compounds. Acta Societiatis Botanicorum Poloniae 74:17-21. 
Grzegorczyk-Karolak I, Kuźma Ł, Wysokińska H (2015a). Study on the chemical composition and antioxidant activity of extracts from shoot culture and regenerated plants of Scutelaria altissima L. Acta Physiologiae Plantarum 37:1736-1740.

Grzegorczyk-Karolak I, Kuźma Ł, Wysokińska H (2015b). The effect of cytokinins on shoot proliferation, secondary metabolite production and antioxidant potential in shoot cultures of Scutelaria alpina. Plant Cell Tissue and Organ Culture 122:699-708.

Hakkim FL, Kalyani S, Essa M, Girija S, Song H (2011). Production of rosmarinic acid in Ocimum sanctum (L) cell suspension cultures by the influence of sucrose, Phenylalanine, yeast extract, and methyl jasmonate. International Journal of Biological and Medical Research 2:1070-1074.

Hamaguchi T, Ono K, Murase A, Yamada M(2009). Phenolic compounds prevent Alzheimer's pathology through different effects on the amyloidbeta aggregation pathway. American Journal of Pathology 175:25572562.

Janicsàk G, Màthè I, Miklòssy-Vàri V, Blunden G (1999). Comparative studies of the rosmarinic and caffeic acid contents of Lamiceae. Biochemical Systematics and Ecology 27:733-738.

Kajani AA, Moghim S, Mofid MR (2012). Optimization of the basal medium for improving production and secretion of taxanes from suspension cell culture of Taxus baccata L. DARU J Pharmaceutical Sciences 20:54-99.

Kakasy AZ, Füzfai Z, Kursinszki L, Malnàr-Parl I, Lemberkovics E (2006) Analysis of non-volatile constituents in Dracocephalum species by HPLCand GC-MS. Chromatographia 63:17-23.

Kikowska M, Budzianowski J, Krawczyk A, Thiem B (2012). Accumulation of rosmarinic, chlorogenic and caffeic acids in in vitro cultures of Eryngium planum L. Acta Physiologiae Plantarum 34:2425 2433.

Kintzios S, Makri O, Panagiotopoulos E, Scapeti M (2003). In vitro rosamrinic acid accumulation in sweet basil (Ocimum basilicum L). 25:205-408

Krzyżanowska J, Czubacka A, Pecio Ł, Przybyś M, Doroszewska T, Stochmal A, Oleszek W (2012). The effect of jasmonic acid and metyl jasmonate on rosmarinic acid production in Mentha $\times$ piperita cell suspension cultures. Plant Cell Tissue and Organ Culture 108:73-81.

Lamien-Meda A, Nell M, Lohwaner U, Bömer A, Franz C, NovakJ (2010). Investigation on antioxidant and rosmarinic acid variation in the sage collection of the Genebank Gatersleben. Journal Agriculture and Food Chemistry 58:3813-3819.

Lima CF, Fernandes-Ferreira M, Pereira-Wilson C (2006). Phenolic compounds protect HepG2 cells from oxidative damage; Relevance of glutathioneleves. LifeScience 21:2056-2068.

Ly TN, Shimoyama M, Yamamuchi R (2006). Isolation and characterization of rosmrinic acid oligomers in Celastrus hindssi Benth leaves and their antioxidative activity. Journal Agriculture and Food Chemistry 54:3786-3793.

Murashige T, Skoog F (1962). A revised medium for rapid growth and bioassay with tobacco tissue culture. Physiologia Plantarum 15:473-497.
Mushtaq N, Schmatz R, Pereira LB, Ahmad M, Stefanello N, Vieira JM, .. Schetinger MR (2014). Rosmarinic acid prevents lipid peroxidation and increase in acetylcholinesterase activity in brain of streptozotocininduced diabetic rats. Cell Biochemistry and Function 32:287-93.

Nikitina AS, Popova OI, Ustarkova LS, Chumakova VV, Ivanowa LI (2008) Studies the essential oil of Dracocephalum moldavica cultivated in theStravropol region. Pharamaceutical Chemistry Journal 42:203-207.

Qian J, Guiping L, Xiujun L, Xincai H, Hongmei L (2009). Influence of growth regulators and sucrose concentrations on growth and rosmarinic acid production in calli and suspension cultures of Coleus blumei. Natural Product Research 23:127-137.

Popova OI, Nikitina AS, Markova OM (2008). Studies of iridoids from Dracocephalum moldavica cultivated in the Stavropol region. Pharmaceutical Chemistry Journal 42:351-353.

Psotova J, ClopcikovaS, Miketova P, Simanek V (2005). Cytoprotectivity of Prunella vulgaris on doxorubicin-treated rat cardiomycetes. Fitoterapia 76:556-561

Pulido R, Bravo L, Saura-Calixto F (2000). Antioxidant activities of dietary phenols are determined by a modified ferric reducing/antioxidant power assay.Journal Agriculture and Food Chemistry 48:3396-3402

Sahraroo A, Mirjalili MH, Purificacion C, Babalar M, Moghadam MRF (2016). Establishment and characterization of a Satureja khuzistanica Jamzad (Lamiaceae) cell suspension culture: a new in vitro source of rosmarinic acid. Cytotechnology 68:1415-1424.

Sanchez-Medina A, Ethridge CJ, Hawkes GL, Hylands PJ, Pendry BA, Hughes MJ, Corcoran O (2007). Comparison of rosmarinic acid content in commercial tinctures produced from fresh and dried limon balm (Melissa officinalis). Journal of Pharmaceutical Sciences 10:455463.

Saxena M, Saxena J, Pradhan A (2012). Flavonoids and phenolic acids as antioxidants in plants and human health. International Journal of Pharmaceutical Sciences Review and Research 16:130-134.

Singlenton VL, Rossi JA (1965). Colorimetry of total phenolic with phosphomolybdic-phosphtungstic acid reagents. American Journal of Enology and Viticulture 16:144153.

Sultan A, Bahang H, Aisa HA, Eshbakova KA (2008). Flavonoids from Dracocephalum moldavica. Chemistry of Natural Compounds 44:366367.

Weremczuk-Jeżyna I, Grzegorczyk-Karolak I, Frydrych B, Królicka A, Wysokińska H (2013). Hairy roots of Dracocephalum moldavica; rosmarinic acid content and antioxidant potential. Acta Physiologiae Plantarum 35:2095-2013.

Wu CF, Kariotu A, Rohr D, Bilia AR, Efferh T (2016). Production of rosmarinic acid and salvianolic acid B from callus culture of Salvia miltiorrhiza with cytotoxicity towards acute lymphoblastic leukemia cells. Food Chemistry 201:292-297.

Zhong JJ, Yoshida YTYT (1995). Recent advances in plant cell cultures in bioreactors. World Journal of Microbiology and Biotechnology 11:461464. 